Portland State University

PDXScholar

6-1-1967

\title{
Aspects of the city; a group of paintings in varied media, based on the theme of the city and river front
}

Frances Evelyn Kimball

Portland State University

Follow this and additional works at: https://pdxscholar.library.pdx.edu/open_access_etds Let us know how access to this document benefits you.

\section{Recommended Citation}

Kimball, Frances Evelyn, "Aspects of the city; a group of paintings in varied media, based on the theme of the city and river front" (1967). Dissertations and Theses. Paper 61.

https://doi.org/10.15760/etd.61

This Thesis is brought to you for free and open access. It has been accepted for inclusion in Dissertations and Theses by an authorized administrator of PDXScholar. Please contact us if we can make this document more accessible: pdxscholar@pdx.edu. 
AN ABSTRACT OF THE THESIS OF

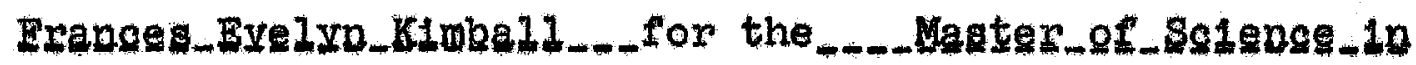

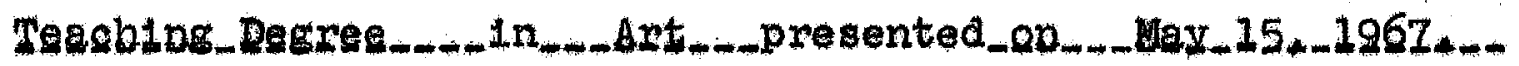

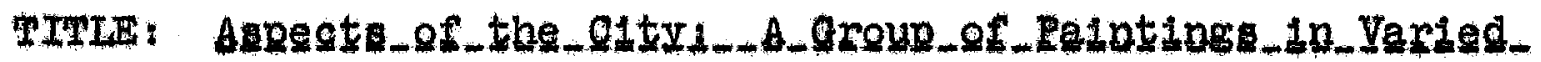
Medta__Based_on_tbe_Tbeug_of_tbe_G1ty_and_B1_er_Iront

ABSTRACT APPROVED:

Riohard J. Prasch

The main purpose of my work was to explore the properties of various palnting media, principaliy those of synthetic composition and at the same time to explore and extend the color range of my palette in order to reflect attitudes of the theme. The aubject was selected because of the unilmited possibilities in composition through the use of the contrasting active and quiet aspects of the clty. The paintings are representational abstracts which I have tried to make function as well-organized compositions without completely destroying the realistlc content. Working with a subject-orlented theme makes each painting a new problem and, therefore, each painting is discussed separately in terms of compostional elements, color relationships and materials employed. 

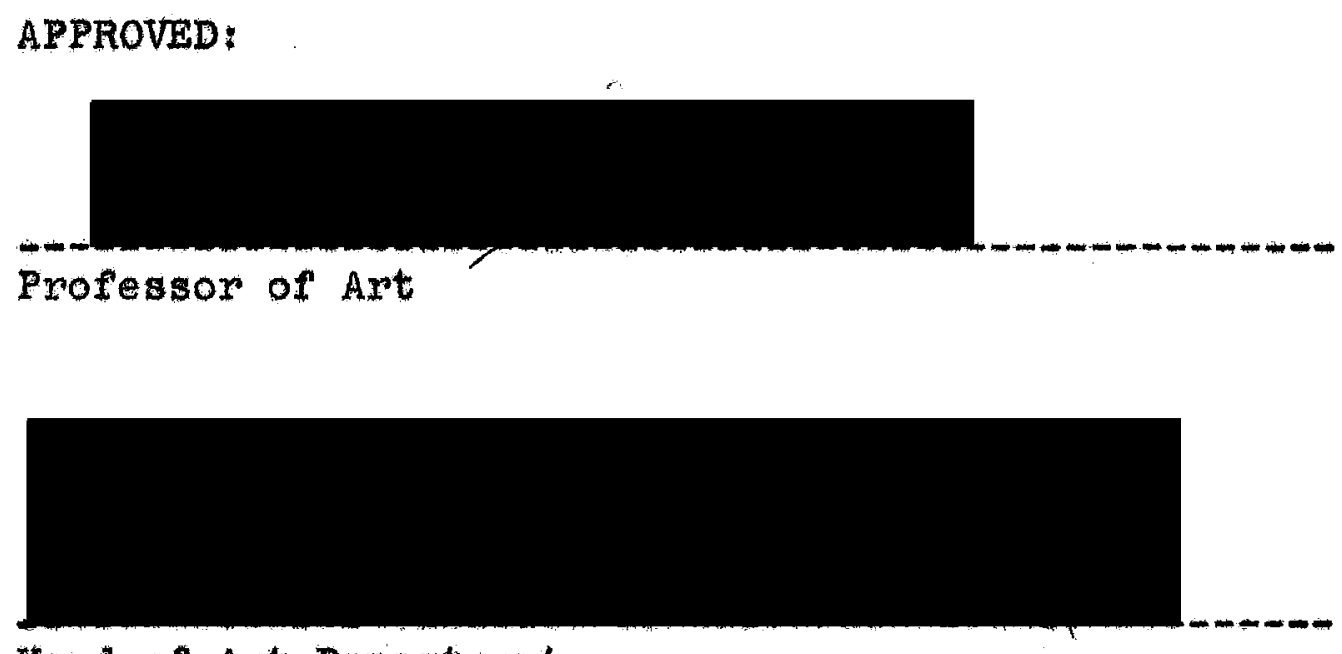

Head of Art Department

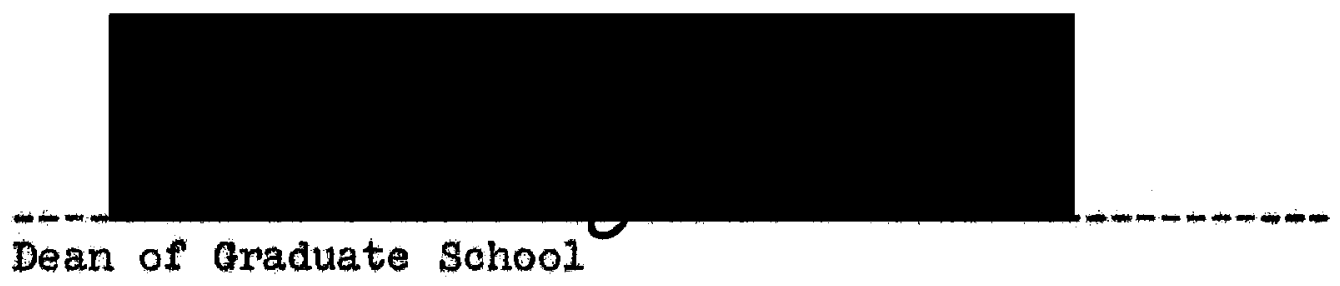

Date Thes1s is presented.27dy 1s 1967.

Typed by Frances Evelyn Kimball 


\title{
Aspects of the Caty
}

A Group of Paintings in Varied Media, Based on the Theme of the C1ty and RIver Front

by

Frances Evelyn KLimball

\author{
A THESIS \\ submitted to \\ Portland State College
}

In partial fulfiliment of

the requirementa for the

degree of

Master of Science in Teaching

June 1967

PORTLAND STATE COLLEGE LIBRARY. 


\section{Aspects of the Clty}

A Group of Paintings in Varied Media, Based on the Theme of the City and River front

The feeling conveyed is the Important factor in art-and there can only be interaction between the viewer and the painting if Iife is refleoted in the work, elther in the form of subject or theme, or by the technique employed. The subject approach transmits feelings about that which is plctured, whereas the technlque approach shows the process of being, of becoming and often has more to give to the public than subjectoriented art. Art whlch is a mirror of nature can be good, but If It is only a dead record of something ilving, then it is more of an insult to the viewer than the accldental happenings which are sometime passed off as modern art. A living abstract, a painting with good qualities of surface texture and color, oan be more exclting and vitally allve than a picture of apeciflc subject. If the message the artist tried to communicate is worthwhile, or the methods employed convey meaning in themselves, then the painting will be successful regardless of the style, and the art will live on. This communication does not have to be a "story teling" type between the artist and his publ10--the symbols he uses may read differently to another person--but the palnting must 
create an emotive response within the viewer. However, an artist first must paint for himself and only incidentally for others.

Some groups of artists assert that representational art is an outmoded form of painting, and I would have to agree if It is "pleturing" simply to prove one can do so. However, I belleve all art is in a sense representational and cannot become outmoded. The artist represents e1ther that which he can see, that which he feels or that which is known but has not yet been visualized by the human eye. Representation does not have to be mirror reflections of objects, but even if the painting is classifled as non-objective, the human mind is such that it responds to stimuli from the world around us and the art becomes representational in this sense. The artist cannot erase all emotional or visual stimuli from his mind-but there a few who try to do so. I don't belleve $1 \mathrm{t}$ is necessary to shut out the world in order to paint "Intellectually". The artist does not have to become so engrossed in the problems of form, shape, color, balance--the elements of composition--that he disregards all else. It is not always an easy task to combine subject matter and form, and in some instances a painting can be good without both of these being present. If the message is strong enough, then the painting w111 "read", regardless of the flaws in composition or in technical sk111. Without subject matter as the basis for the palnting, however, all else depends on the intellectual artistic 
devices and techniques and the artist must be well acquainted with these technical skilis.

I do not belleve that an artist must seleot e1ther content as his forte, or that he must rely solely on these artistic devices, but that, if possible, a balancing of the two ends of this "artist1c scale" is to be desired. It is this balance that I attempt to achieve in my own paintings, although at this stage of development, I retaln far more of the realistic tendencles by being very much aware of the visual world around us, I am not a soientist who sees into the structure of objects as many artists do, but I do feel "about" things and try to incorporate these feelings in my work. Most of my paintings are relatively small in size, due partiy to the physical 11mitations of transporting and storing, but also because I feel that the size of a canvas determines to some extent where it w111 be placed. (Many artists are forcing art out of our everyday life simply by insisting on enormous proportions which demand large wall areas, to be found only in the institution of the art museum.) I enjoy working on a larger canvas because 1t allows one more freedom. We should not abandon the large canvas--they are Important-but there is atill a place for smaller paintings as well. 
A Kodak camera was used for all of the photographs, which were taken at the same time under the same lighting conditions, with Kodacolor film. I have left some of the background showing around each painting so that one can compare value and intensity of the painting with the background. The paintings were photographed against a white canvas, but unfortunately, as one can see, most of the borders are of an off-white, a result of improper development. The size of each canvas is indicated in inches, and they are arranged in sequence as they were completed. Where the term "acryl1e" is used, I am referring to acryllc polymer emulsion ("L1quitex" brand by Permanent Plgments, Ino.) whioh Is packaged in tube containers and which has a low sheen characteristio to oll paints.

\section{Painting No. 1 and No. 2}

The flrst and second compositions are from the same scene, the flrst being rendered in water colors on a heavy grade water color paper and the second in acrylies on canvas board. The water color was made several weeks before the second painting, thus the basic color change is due to seasonal changes as much as to arbitrary color selection. By using the same subject in more than one painting, I hope to free myself of the subject and the Inear aspects, and to paint more openly, more freely, concentrating on the compositional elements rather than content, The second painting 
in acrylics, is mixed with gel medium which retards drying time and gives the paint a quality very near that of 011. Texture is acquired as the result of scumbling, of being painted over another composition and belng painted in several sessions. I focused my attention on the diagonals of the bulldings and have incorporated these geometric movements in the landsoape that background and subject work together as an integrated structure. Warm colors were used to reflect the dry, hot attitude of the actual setting.

\section{Palnting No. 3}

Carrying out the theme approach to painting, I have tried to capture the feeling of the quiet of early morning in the clty, with the haze still lingering over the river. Again, I have used acryllos and have tried to eliminate most hard edges from the composition, working in a painterly fashion. The palette is in muted colors, in the cool bluegrey-green range, with warm yellow ochres and browns for atmospherte contrast. (The browns do not come through as strongly in the original painting as they do in the photograph.) The view 1 from above the river with tree tops visible in the foreground to carry the eye up into the scene, With this painting I have done some experimenting with surface texture by mixing the gesso base with sand, so that the brush often skims over the roughness, showing the underpainting beneath. There has been no particular attempt at 
Painting No. 1

"Warehouses - I"

$18 \times 22$, water color
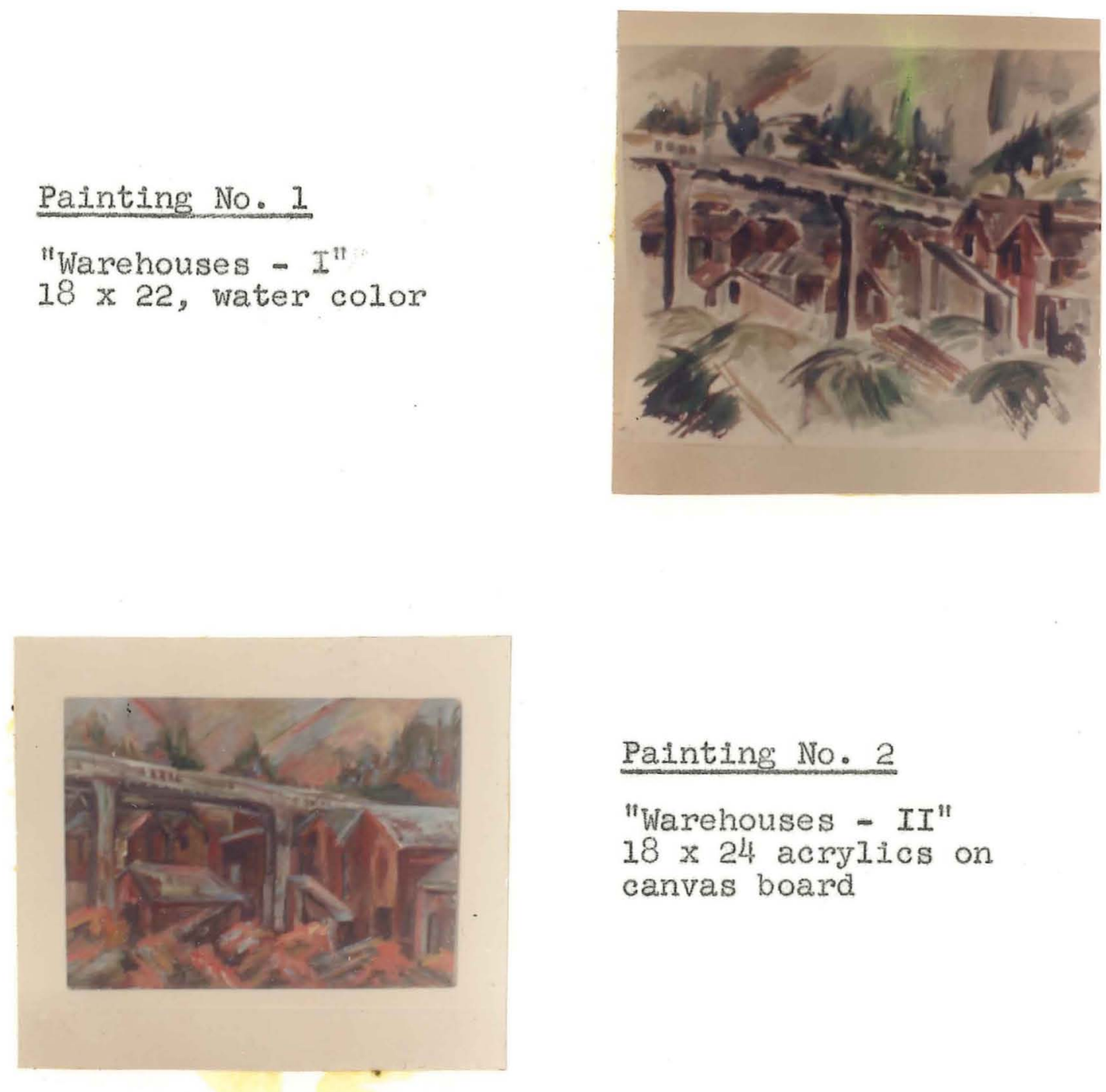

Painting No. 2

"Warehouses - II" $18 \times 24$ acrylics on canvas board

Painting No. 3

"Morning"

$19 \times 24$ acrylic on canvas board.

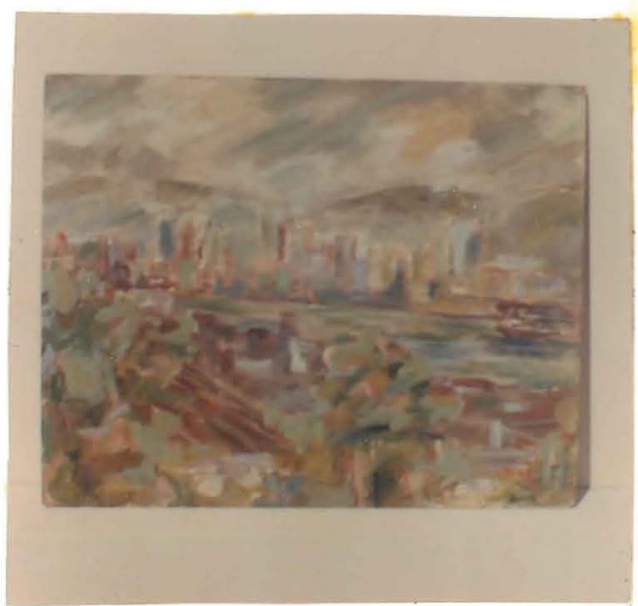


Inear perspective, however, there is depth achieved through the use and placement of warm and cool, dark and 11ght colors. The colors are low in intensity with only incidental touches of orange for accent, and in some places where the paint skims over the surface, the white of the canvas shows through.

\section{Painting No. 4 and No. 5}

Painting No 4 is in water colors (Winsor \& Newton brand) on a 11ght weight paper, with large areas of white remaining. In No. 5 I have used the wateroolor as a basis for this acrylic, which also is rendered in the traditional oll painting technique, with warm underpainting of yellow ochre and burnt umber, and predominately cool blues, greens and greys applied more thickly ove this. In this painting I have tried to capture the quietness of the river, without painting what I have referred to a "dead representation of a living scene". By keeping the brush strokes separate and laying one color over another, the technlque breaks the monotony of the large area shapes of water and sky. This scene was more successfully rendered in water colors; st111 it is not a true representation of the scene, but an attempt to capture the menacing mood of the river. There is less detail in the larger painting, as I have tried to emphasize the large shapes and to simplify the masses of 11ght and dark, while keepling the shapes active by the use of separate brush strokes. 
Painting No. 4

"Ritver"

$15 \times 22$ water color

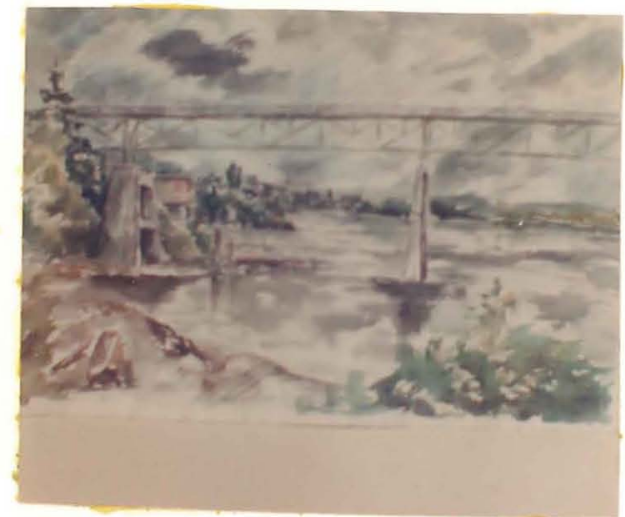

Painting No. 5

"River II"

$31 \times 41$ acrylies

on scretched canvas

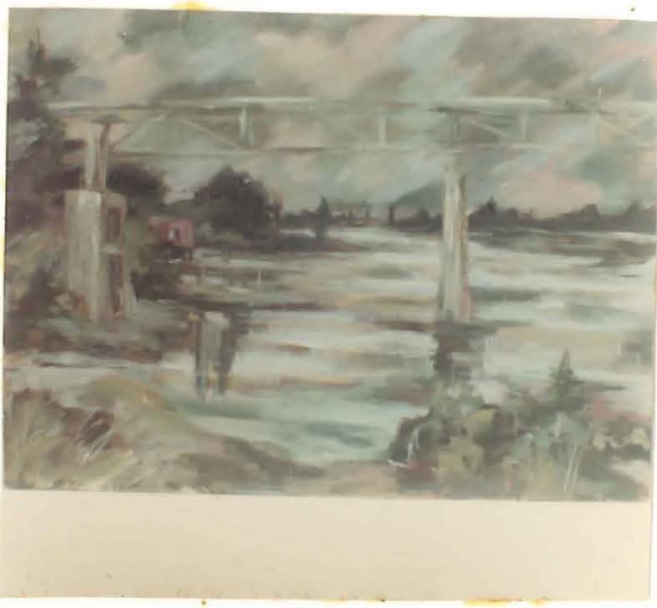


Painting No. 6

Fliokering 11ght and reflections are the first thoughts of the city that come to my mind, and in painting No. 6 I have tried to capture these impressions of the ofty at night. The painting is a composite of the buildings of Portland as seen from across the WIllamette. Color sketches were made on the spot and constant v1sits to the site were made for revisions in the painting. The entire canvas is rather low in key, with the reflections being built up by layers of transparent washes of burnt umber, blue-green and violets creating soft tonalities. Trying to retain basic shape and separate value areas, the bulldings and light colors were added in opaque "gmears" so they remain an integrated part of the painting. I have used oll glazes over the darkest areas to increase the transparent, reflective qualitles and, further, to make the dark and 11 ght values fit together as large area shapes. The accent colors also are "smeared" on so they remain integrated spat1ally without jumping out of the dark panel. There is a dissolution of sharp edged forms throughout in order to emphasize the character of the ofty at night.

\section{Painting No. 7}

In order to free myself further from pure representation, I chose to work with collage, and painting No. 7 is an example of the experimenting done with this technique. The surface 


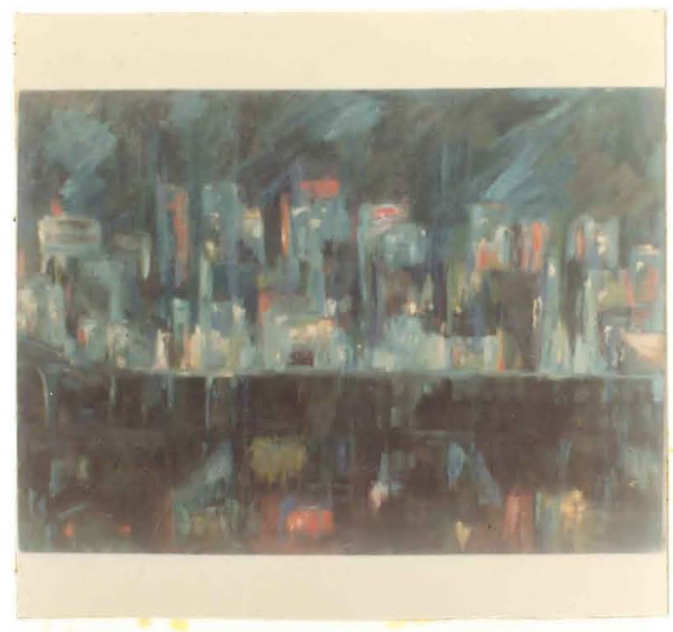

Painting No. 6

"Reflections" $26 \times 36$ oil on stretched canvas

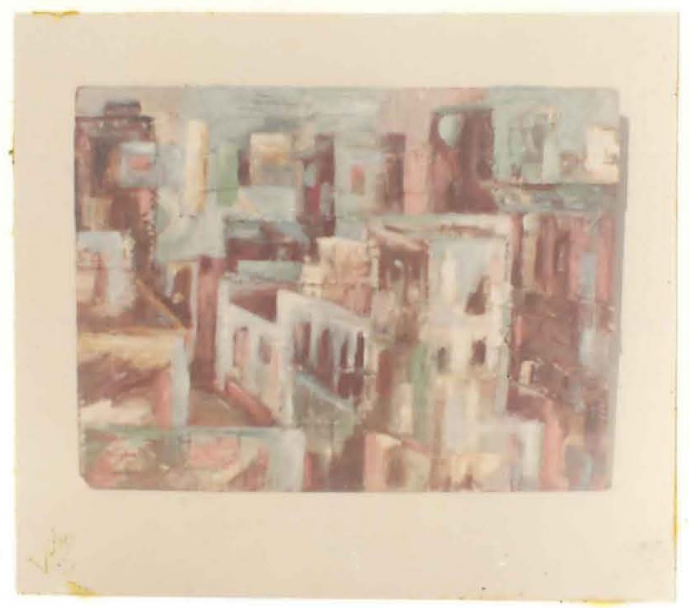

Painting No. 7

"Builalngs". $18 \times 22$ collage on masonite 
is the rough side of masonite, textured even further with the addition of shapes of torn canvas added before and during the process of painting. Acrylics were used, together with the gel medium as a fixative for the pleces of net, string, paper and cloth. Th1s collage shows, perhaps more clearly than any of the other paintings, the confliot of subject and technique, for It is evident that I cannot entirely separate myself from the visual world around me, whlle trying to employ the artistic techniques of abstrgetion. The diagonal ine on the left gives a suggestion of perspective, but the overlapping areas in the background negate the spatial concept and the bulldings are represented in a third dimensional setting while much is retalned of the second dimensional surface of the collage. A warm and cool color relationship is tressed and much scumbling and scraping has also been done to achleve the weather-worn look of old bulldings, Color planes altemate between warm and cool within the basic forms to further emphasize texture and surface richness (whlch do not photograph well). Th1s painting was not altogether successful, but was an attempt to break with the representational pattern. Further study in collage will be helpful toward this end.

Painting No. 8

This painting is a combination of o1l and acrylics used in the traditional oll painting technique--oil being used first, then acrylics and oll combined (not actually 
mixed but in altemate ary layers of color). Just how well the canvas will hold up, I do not know, for some manufacturers of acrylics protest that these paints will not adhere to the ol1 surface, however, I found this to be no problem (as yet after several months). The subject is an old cooperage in a very run down state of repair, with many projecting rooms and numerous doors, and these geometric shapes make the number of studies unlimited. I have tried to capture the two aspects of this bullding, the active and the quiet, through the many diagonals used and the contrating color soheme of warm and cool colors. I classify this as a representational abstract, for there have been modifleations in the actual structure to fit the shape of the canvas and modifleations in color to reflect the mood, and yet, it 1s still recognizable as some type of mill.

\section{Painting No. 9}

While working with the cooperage, I found many problems which perplexed me in the use of reds and oranges. So, for further exploration in this warm range of colors and to break away from my theme for awhlle, I turned to the organtc forms of nature, and painting No. 9 is the result of one such studies. It is an introspection of an organic structure--the pepper-made rapldiy with only two or three later alterations. Acrylios are the media used on canvas board with a base of gesso mixed with salt for texture. Deep violets and dark hookers green 
Painting No. 8

"Cooperage"

$20 \times 46$ mixed media
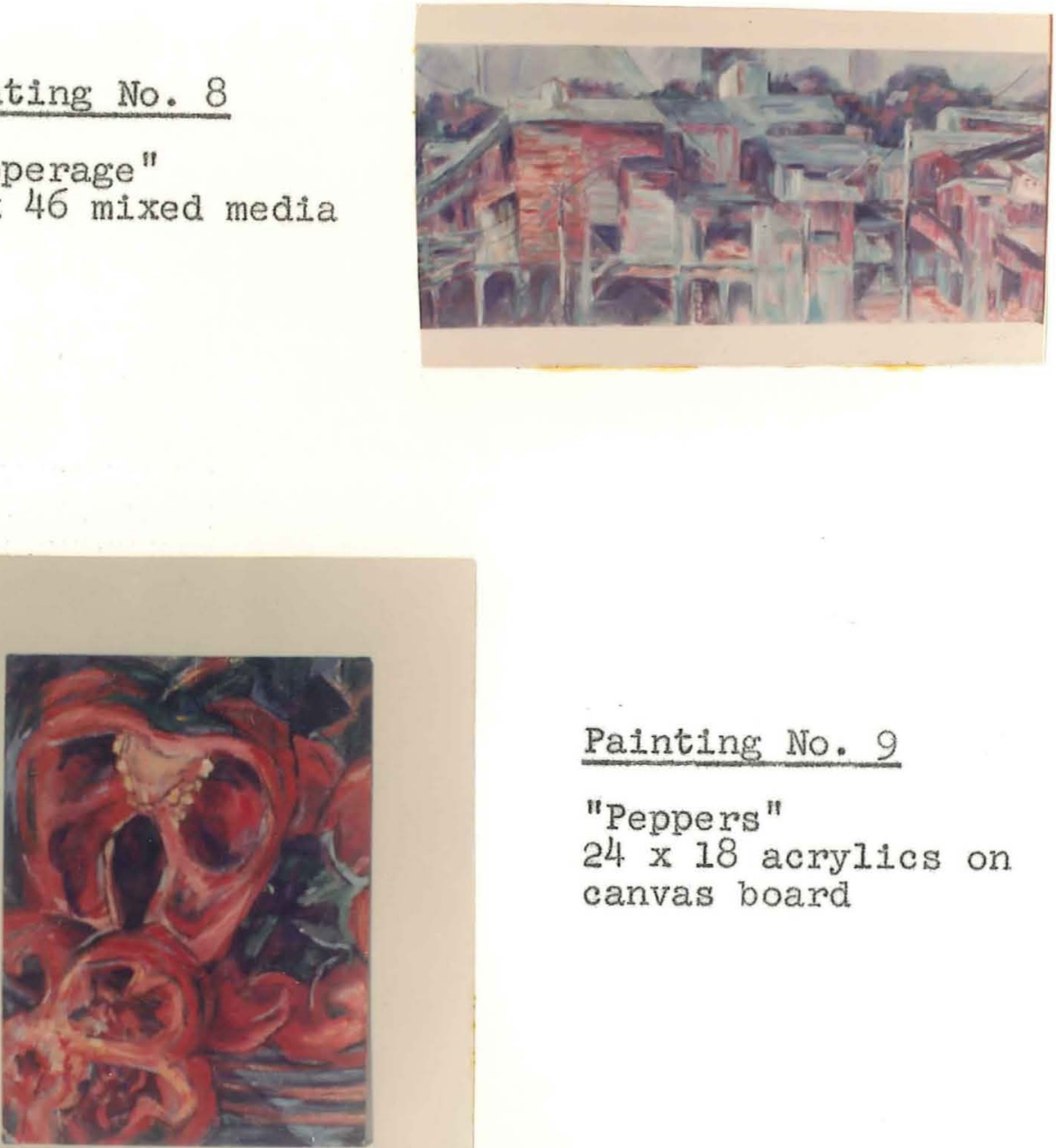

Painting No. 9

"Peppers"

$24 \times 18$ acrylics on canvas board

Painting No. 10

"Study in Red"

$20 \times 46$ acrylic collage

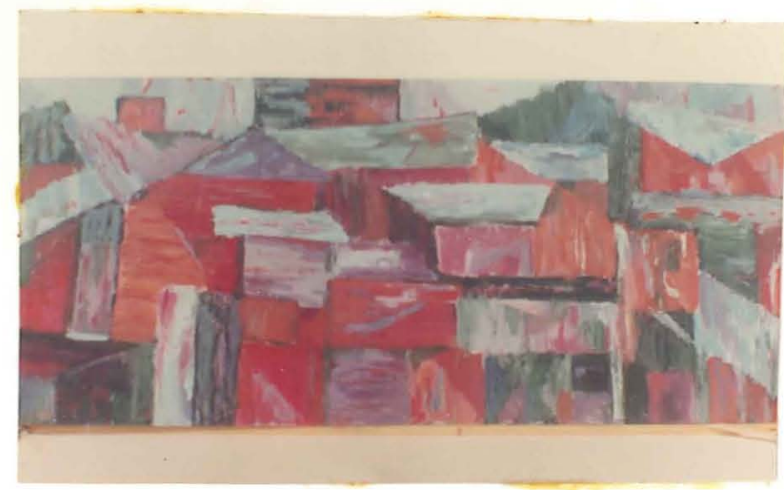


were used as the underlying wash with thicker impasto-like reds and cobalt and ultamarine blue accents applied over the wash. Charcoal lines flow in and out of the shapes to emphasize the organic structure.

\section{Painting No. 10}

After the peppers painting, I returned to the complexities of the cooperage and No. 10 is the result. I have tried to simplify the forms and continue to work with the reds and blue-greys which gave me trouble with the flrst cooperage palnting. I declded to work with the same shape canvas, but to simplify and clarify the geometric shapes. After many revisions in approach, I finally decided that some Iine accent was necessary and have used a very dark hookers green--almost black-for several divisions of the areas and then painted the color into the lines. Strips of plastle were crumpled and applied with gel medium to glve texture to the smooth slde of the untempered masonite board, and some scraping was done for more texture. A wide range of reds and oranges were used, however, they do not show up well in the photograph.

\section{Painting No. 11}

Dally drives by this location each evening kept this scene fresh in my mind and photographs also were used as a basis for this painting. Th1s, also is on the textured side of a masonite board and is painted with acrylics in the 
traditional building-up process of oll painting. My intent was to capture the essence of early evening when thousands of lights vibrate in reflections on the river. The accent lights were applied as the painting progressed, thus they do not jump out aggressively from the canvas. This night scene is In 1 ighter values than painting No. 6 , yet st1ll retains the effect desired.

Painting No. 12

Another aspect of the city is deploted in this canvas, again the panorama, since I feel that the eIty is an inanimate thing and only becomes allve and real when there is communication with people, Once in the c1ty it becomes an organization of life, but this view is the way I see it most often. There has been another change in the range of palette colors in this, with violet and yellow as the basic colors. The sky area is entirely in the violet range and the city itself contrasts in the bright sunlight--a if after a cloudburst. Due to difficulties presented by trying to paint this scene on the spot, I worked from photographs, but revigited the scene frequently for fresh Impressions, Here again, I have returned to closer representation of the subject, but with loosely applied brush strokes and broken patches of color.

Painting No.13 and No. 14

The ofty from a distance presents beautiful patterns and shapes of light and dark, particularly when there is 


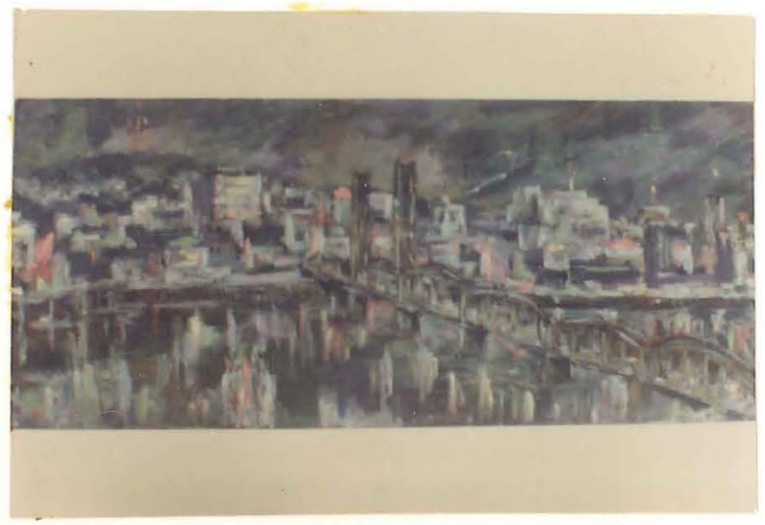

Painting No. 11

"City at Night"

$20 \times 46$ acrylic on masonite

Painting No. 12

"After Rain"

$26 \times 48$ acrylic on canvas 


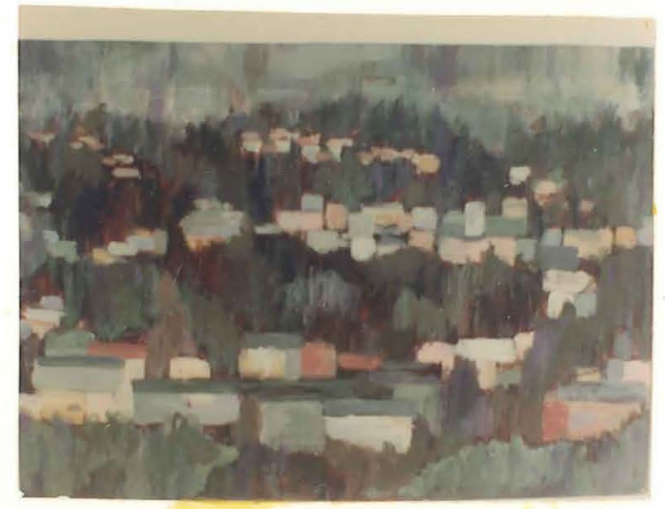

Painting No. 13

"Northwest HIIIs" $22 \times 31$ acrylic on upson board

Painting No. 14

"Patterns" $24 \times 46$ acrylics on canvas

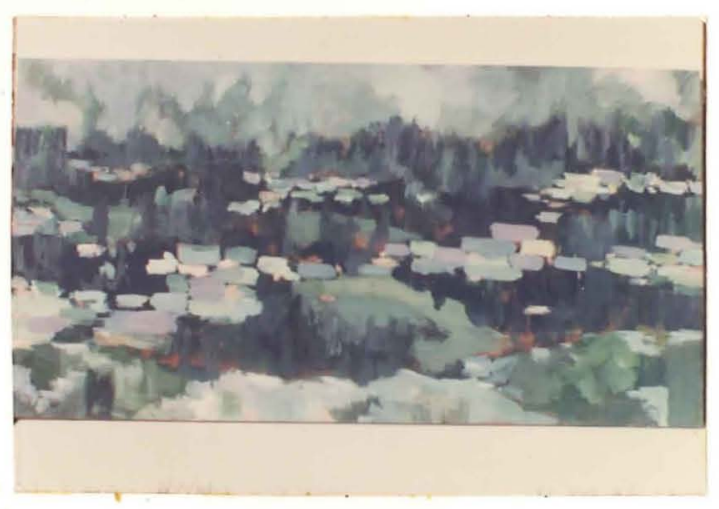


vegitation to separate the man-made structures. Such a darklight pattern is to be found in the northwest hills of Portland and this location was the basis for painting No. 13. The buildings no longer interest me as separate structures, but as they present a pattern against the dark hills, they became subject matter for an interesting composition. (This small painting is made of acrylics on upson board.) No. 14 is a further study of the same dark-1ight pattern and is but one step further in the direction of abstraction, as the color areas tend to float one on top of the other. Painting No. 13 is more successful in relating the areas, but No. 14 is more alive than the first. This last painting is handled very loosely in vertical and horizontal strokes of opaque color over a thin burnt sienna base, giving it more suggestion of depth and more abstract qualities. It is included in this collection an Indication of the direction I Intend to pursue in further studies. It approaches abstraction more nearly than any of the others and yet, it is stili based on content. 
Working with synthetic paints is very much like working with oils, except that one is able to work faster due to the quick drying process. Whenever I begin a new painting, it flows easily, almost subconsclously and it is at this point that I reel I should stop--with just the barest suggestion of a composition. Frequently, when working with water colorg, I am forced to stop at this stage and I am usualiy more satisfled with the results obtained. Water colors tend to free me more from the subject and I feel that I use them more successfully than any other media. Perhaps with further exploration in acrylios and other mixed media I w1Il become less "tled down" to content and the artistic soale between content and form will become balanced-at least I shall continue to work to achieve this balance. 


\section{BIBLIOGRAPHY}

Combrich, E.H. Meditations on a Hobby Horse. Connecticut: Phation Publishers, Inc., 1963.

Jensen, Lawrence N. Synthet1a PaInt1ng Media. New Jersey: Prentice Hall, Ino., 1964.

Langer, susan. Reflectlons on Art. New York: Oxford University Press, 1961 . 